\title{
A geochemical record of environmental changes in sediments from Sishili Bay, northern Yellow Sea, China: Anthropogenic influence on organic matter sources and composition over the last 100 years
}

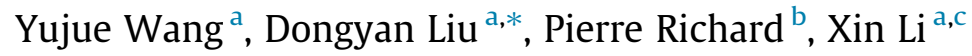 \\ ${ }^{a}$ Key Laboratory of Coastal Environmental Processes and Ecological Remediation, Yantai Institute of Coastal Zone Research, Chinese Academy of Sciences, Yantai, \\ Shandong 264003, PR China \\ ${ }^{\mathrm{b}}$ Littoral, Environnement et Sociétés, UMR 7266 CNRS-Université de La Rochelle, 2 rue Olympe de Gouges, 17000 La Rochelle, France \\ ${ }^{\mathrm{C}}$ Graduate University of the Chinese Academy of Sciences, 100049 Beijing, PR China
}

\section{A R T I C L E I N F O}

\section{Keywords:}

Anthropogenic influence

Organic matter sources

Marine sediment

Geochemical indicator

Sishili Bay

\begin{abstract}
A B S T R A C T
Total organic carbon (TOC), total nitrogen (TN), $\delta^{13} \mathrm{C}$ and $\delta^{15} \mathrm{~N}$ were measured in sediment cores at three sites in Sishili Bay, China, to track the impacts of anthropogenic activities on the coastal environment over the last 100 years. The increased TOC and TN in the upper section of sediment cores indicated a eutrophic process since 1975. In comparison, the TOC and TN in the sediment core near to a scallop aquaculture area displayed a much slower increase, indicating the contribution of scallop aquaculture in mitigating eutrophication. Combined information from $\delta^{13} \mathrm{C}, \delta^{15} \mathrm{~N}$ and TOC:TN indicated an increased terrestrial signal, although organic matter sources in Sishili Bay featured a mixture of terrestrial and marine sources, with phytoplankton being dominant. Increased fertilizer use since 1970s contributed to the eutrophic process in Sishili Bay since 1975, and increased sewage discharge from 1990s has added to this process.

(c) 2013 Elsevier Ltd. All rights reserved.
\end{abstract}

\section{Introduction}

Coastal eutrophication due to intensive anthropogenic activity is a common environmental issue around the world (de Jonge et al., 2002). In China, major environmental changes have occurred over recent decades as a result of rapid economic development, and many coastal waters have been characterized by considerable nitrogen overloading (e.g., the Yangtze River, the Bohai Sea and Jiaozhou Bay) (Liu et al., 2005; Chai et al., 2006). Sishili Bay is located in the northern Yellow Sea, China (Fig. 1) and over the last two decades has been developed as an important harbor and coastal aquaculture base by the local government of Yantai city. Consequently, eutrophication caused by the increased population, large-scale marine aquaculture and sewage discharge along the coast have significantly impacted the health of the marine ecosystem. Harmful algal blooms and jellyfish blooms in the bay have occurred almost annually over the last 10 years (Wu et al., 2001; Dong et al., 2010; Hao et al., 2011). Thus, it is important to understand the sources of different pollutants and eutrophic processes

* Corresponding author. Address: Yantai Institute of Coastal Zone Research, CAS, 17th Chunhui Road, Laishan District, 264003 Yantai, PR China. Tel./fax: +86 535 2109116.

E-mail address: dyliu@yic.ac.cn (D. Liu). ahead of the development of a policy for environmental protection and restoration in Sishili Bay.

Organic matter preserved in coastal sediments can provide useful information to interpret the processes of past environmental change, the effects of human activities and even related climatic signals (Meyers and Lallier-Verges, 1999; Bratton et al., 2003; Cooper et al., 2004; Gonneea et al., 2004). Stable carbon and nitrogen isotope $\left(\delta^{13} \mathrm{C}\right.$ and $\left.\delta^{15} \mathrm{~N}\right)$ ratios and the ratio of total organic carbon (TOC) to total nitrogen (TN) in sediments (TOC:TN) have been widely used to elucidate the source and fate of organic matter in the marine environment (Fry and Sherr, 1984; Mishima et al., 1999; Ogrinc et al., 2004; Ramaswamy et al., 2008). The TOC:TN ratio is an important indicator of the origin of organic matter, as there are obvious differences between different organic matter sources. For example, phytoplankton is usually approximately 6.7-10.1, bacteria ranges from 2.6 to 4.3, and high terrestrial vegetation is generally greater than 15 (Meyers, 1994; Cifuentes et al., 1996). However, organic matter breakdown (mineralization) can reduce the carbon and nutrient concentrations in the sediment. Oxidation in the water column or on the sediment surface can significantly impact the TOC:TN ratios (Andrews et al., 1998; Waterson, 2005; Kuwae et al., 2006).

In contrast to the TOC:TN ratio, $\delta^{13} \mathrm{C}$ only changes slightly during the sedimentation, degradation and transformation of organic matter in marine environments; thus, $\delta^{13} \mathrm{C}$ has become a powerful 


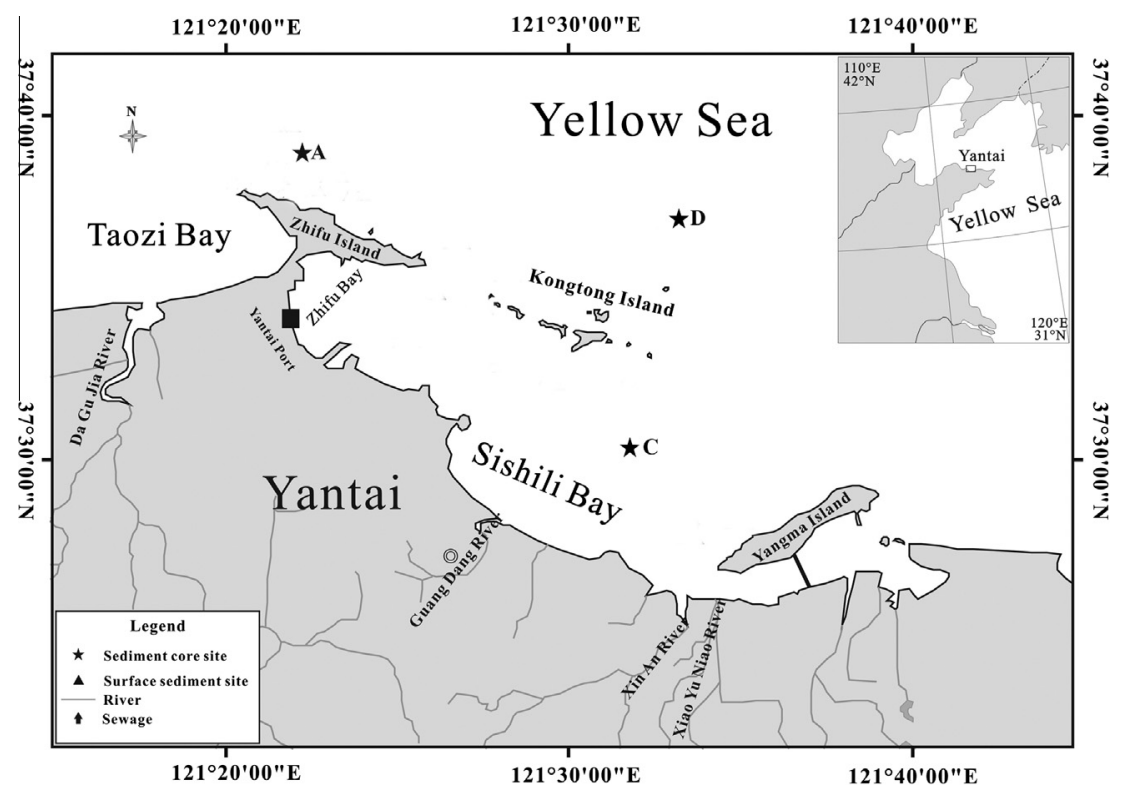

Fig. 1. Maps showing study area and sampling sites in Sishili Bay, China.

tool in deciphering the origin of organic matter (Andrews et al., 1998; Wu et al., 2002; Ramaswamy et al., 2008). In addition, $\delta^{15} \mathrm{~N}$ in the sediments can reflect the deposition rate of terrestrial organic matter, the nitrogen source types for phytoplankton and decomposition processes (e.g., denitrification). However, the fractionation of $\delta^{15} \mathrm{~N}$ during the absorption and assimilation of phytoplankton depends on the concentration and species of inorganic nitrogen (Owens, 1985; Mishima et al., 1999; Cohen and Fong, 2005). Normally, $\delta^{15} \mathrm{~N}$ is used as a subsidiary factor for special events; for example, an increase in organic matter $\delta^{15} \mathrm{~N}$ values can record deliveries of isotopically heavy nitrate $\left(\delta^{15} \mathrm{~N}=10\right.$ 25\%o) from farm runoff and human sewage (Teranes and Bernasconi, 2000; Ramaswamy et al., 2008; Sampaio et al., 2010).

In comparison, the combined use of $\delta^{13} \mathrm{C}, \delta^{15} \mathrm{~N}$ and TOC:TN ratios can help improve the discrimination of organic matter sources from the confusion caused by various biogeochemical processes (e.g., microbial activity, denitrification), particularly in estuaries and coasts with a high mixture of terrestrial and marine matter (Matson and Brinson, 1990; Thornton and McManus, 1994; Andrews et al., 1998; Graham et al., 2001; Ogrinc et al., 2004; Ramaswamy et al., 2008).

In this study, a chronology of organic matter inputs was studied based on sediment cores collected from three sites in Sishili Bay, with an aim to understand the impacts of increased human activity and land-sourced input to the coastal environment over the last 100 years. The geochemical parameters of TOC, TN, $\delta^{13} \mathrm{C}$ and $\delta^{15} \mathrm{~N}$ were used to track the organic matter composition, changes and the potential indication of eutrophication over the last 100 years. The results were evaluated by comparing them with other ecological information, available data on the upper water body, and the socio-economic development of Yantai city.

\section{Materials and methods}

\subsection{Study area}

Sishili Bay is a semi-closed coastal bay surrounded by Zhifu Island and Yangma Island, with northwest-southeast extent of $20 \mathrm{~km}$, a width of $6-7 \mathrm{~km}$ and a total area approximately 130 $\mathrm{km}^{2}$ (Fig. 1). It is a typical temperate coastal area with a temperature of $23.3-27.4{ }^{\circ} \mathrm{C}$ in summer and $2.5-3.5^{\circ} \mathrm{C}$ in winter. Four small ephemeral rivers (Guangdang, Majia, Xin An and Xiao Yuniao) flow into Sishili Bay (Wu et al., 2001), where the salinity ranges from 29.6 to 33.0 during the wet and dry seasons, respectively. The hydrodynamic processes are mainly controlled by tidal movement and wind-induced currents (Zhang and Dong, 1990).

Three sites (A, D and C) were chosen for sediment cores collection in Sishili Bay (Fig. 1). Site A is close to sewage outfalls; Site D is relatively far from the shore and is an area with less effect of human activity; and site $C$ is in a shellfish aquaculture area close to the outlet of the Guangdang River. Four sediment cores were obtained at each site in December 2008 using a gravity corer with a $10.5-\mathrm{cm}$ internal diameter. The cores were sectioned at $1-\mathrm{cm}$ intervals within $24 \mathrm{~h}$ of collection, and then freeze-dried in the laboratory. One core was used for dating analysis, one was used for geochemical analysis, one was used for ecological analysis and the last was used as a back-up.

Suspended particulate organic matter (SPOM) samples were determined to compare the geochemical information and differences of organic matter between the water column and the surface sediment. Samples were collected from the surface, middle and bottom layers of the water columns at each site in March 2010. The sampling water depths at site A were $1 \mathrm{~m}, 12 \mathrm{~m}$ and $25 \mathrm{~m}$, respectively; the depths at site D were $1 \mathrm{~m}, 11 \mathrm{~m}$ and $22 \mathrm{~m}$, respectively; and the depths at site $C$ were $1 \mathrm{~m}, 5 \mathrm{~m}$ and $10 \mathrm{~m}$, respectively. Samples for TOC, TN, $\delta^{13} \mathrm{C}$ and $\delta^{15} \mathrm{~N}$ analysis were collected by filtering $100 \mathrm{~mL}$ water using $13-\mathrm{mm}$ precombusted $\left(450^{\circ} \mathrm{C}\right.$ for $\left.4 \mathrm{~h}\right) \mathrm{GF} / \mathrm{F}$ glass-fiber filters (Whatman) immediately after sampling. The samples were freeze-dried and kept frozen until analysis.

\subsection{Core age measurement}

${ }^{210} \mathrm{~Pb}$ and ${ }^{137} \mathrm{Cs}$ radiometric-dating techniques (Goldberg, 1963; Oldfield and Appleby, 1984) were used to measure the chronology of the sediment cores at the Institute of Geography and Limnology, Chinese Academy of Sciences. Radiochemical measurements were performed using well-type Ge detectors (Model Ortec HPGe GWL). The ${ }^{210} \mathrm{~Pb}$ and ${ }^{137} \mathrm{Cs}$ activities were given after correction with standard samples provided by the Chinese Institute of Atomic 
Energy Research and the University of Liverpool. Sedimentation rates were calculated using the Constant Rate of ${ }^{210} \mathrm{~Pb}$ Supply (CRS) model (Joshi and Shukla, 1991).

\subsection{TOC, TN, $\delta^{13} C$ and $\delta^{15} N$ analysis of sediment cores and SPOM}

The sediment samples were homogenized by grinding after freeze-drying and were then acidified to remove inorganic carbon by adding $1 \mathrm{~mL}$ of $0.5 \mathrm{M} \mathrm{HCl}$ to every $100 \mathrm{mg}$ of sample. The samples were blow-dried under $60^{\circ} \mathrm{C}$, and Milli-Q water was then added to wash out the extra acid. The samples were then freezedried and placed in $5 \times 8-\mathrm{mm}$ tin capsules. Stable isotope measurements were made using a continuous-flow isotope-ratio mass spectrometer (Delta V Advantage, Thermo Scientific, Germany) coupled to an elemental analyzer (Flash EA1112 Thermo Scientific, Italy). Reference gases were calibrated against International Reference Materials (IAEA-N1, IAEA-N2 and IAEA-600 for nitrogen; USGS-24, IAEA-CH6 and IAEA-600 for carbon). The results are expressed relative to Vienna PeeDee Belemnite and atmospheric $\mathrm{N}_{2}$ for $\delta^{13} \mathrm{C}$ and $\delta^{15} \mathrm{~N}$, respectively. Replicate measurements of a laboratory standard (acetanilide, Thermo Scientific) analyzed with the samples indicated that the analytical errors were $<0.1 \%$ for both $\delta^{13} \mathrm{C}$ and $\delta^{15} \mathrm{~N}$. The TOC:TN ratios were determined from the \%TOC and \%TN data obtained as part of the stable isotope analyses.

The SPOM samples were acidified using $\mathrm{HCl}$ fumes for $4 \mathrm{~h}$ after freeze-drying and were then placed in $5 \times 8-\mathrm{mm}$ tin capsules. TOC, $\mathrm{TN}$ and stable isotopes of $\mathrm{C}$ and $\mathrm{N}$ were analyzed and calculated in the same way as for the sediment samples.

\subsection{Sediment grain size analysis}

The grain sizes of the sediment samples were measured using a Mastersizer 2000 Laser Particle Sizer. The grain sizes were classified into 4 groups: less than $4 \mu \mathrm{m}$ for clay, $4-64 \mu \mathrm{m}$ for silt, and larger than $64 \mu \mathrm{m}$ for sand. Before the grain-size measurements, the samples were oxidized using $10 \% \mathrm{H}_{2} \mathrm{O}_{2}$ to remove organic matter and were dispersed in a $0.05 \%$ sodium hexametaphosphate solution to separate discrete particles.

\subsection{Data analysis}

Correlation analyses among the parameters were analyzed according to a 2-tailed test using the SPSS 11.5 (Statistical Product and Service Solutions) software. Fig. 1 was prepared using MapGIS 7.0, and other figures were produced using Grapher 8.0.

\section{Results}

\subsection{Sediment chronology and grain size analysis}

The excess ${ }^{210} \mathrm{~Pb}\left({ }^{210} \mathrm{~Pb}_{\mathrm{ex}}\right)$ activities of the three sediment cores showed an approximately exponential recession, with some subfluctuations (Figs. 2-4). The variability in the ${ }^{210} \mathrm{~Pb}_{\mathrm{ex}}$ activity, particularly over the surface $20 \mathrm{~cm}$, supports the application of the CRS model to estimate the sedimentation rate of the core (Appleby et al., 1986). The calculated average sedimentation rate indicated a time span of ca. $1865-2008$ for core A ( $=0.70 \mathrm{~cm} /$ year), ca. $1876-$ 2008 for core D ( $=0.91 \mathrm{~cm} /$ year), and ca. $1858-2008$ for core C $(=0.78 \mathrm{~cm} /$ year $)$.

The ${ }^{137} \mathrm{Cs}$ activities were first found at a depth of approximately $26 \mathrm{~cm}$, and two peaks appeared at depths of 14.5 and $5.5 \mathrm{~cm}$ in core $\mathrm{A}$, corresponding to the worldwide atomic bomb testing in approximately 1975 and the Chernobyl nuclear station release accident in 1986 . For core D, the ${ }^{137} \mathrm{Cs}$ activity peaks at depths of $40.5,16.5$ and $8.5 \mathrm{~cm}$ corresponded to the worldwide atomic bomb

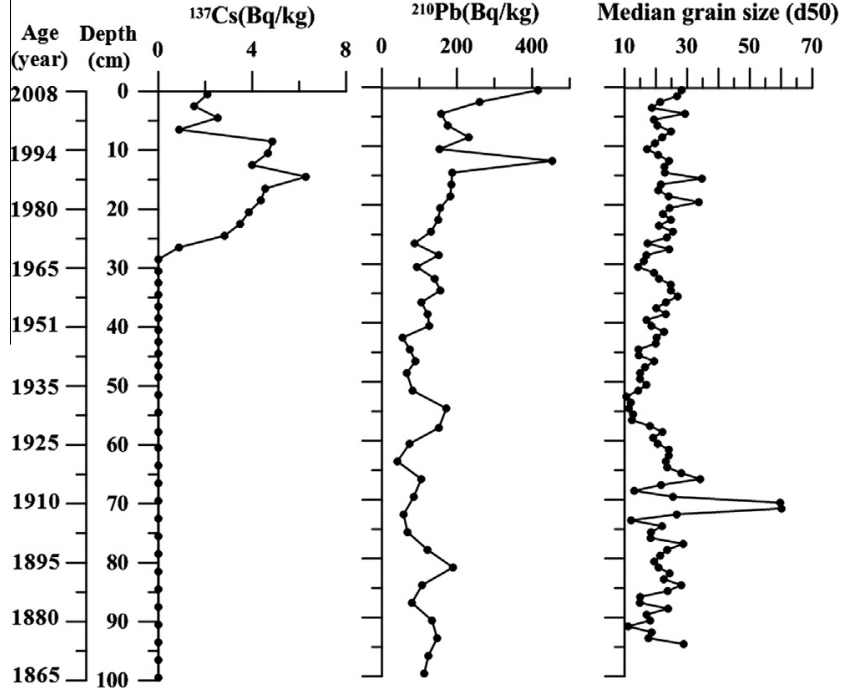

Fig. 2. ${ }^{137} \mathrm{Cs}$ and ${ }^{210} \mathrm{~Pb}$ activities and median grain size (d50) versus depth of core $\mathrm{A}$.

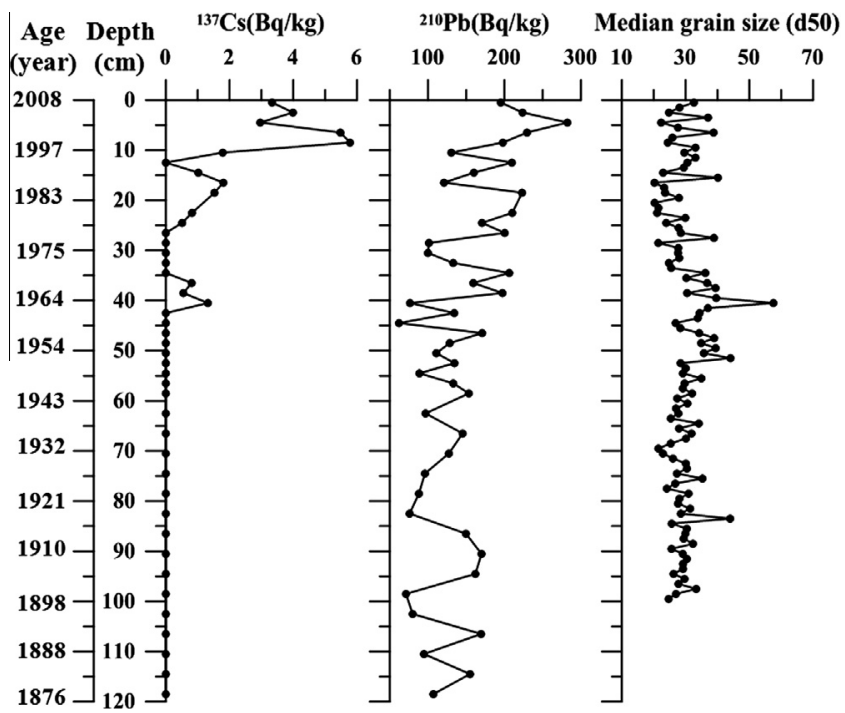

Fig. 3. ${ }^{137} \mathrm{Cs}$ and ${ }^{210} \mathrm{~Pb}$ activities and median grain size (d50) versus depth of core $\mathrm{D}$.

testing in 1963 and in 1975 and the Chernobyl nuclear station accident in1986, respectively. Similar to core A, the ${ }^{137} \mathrm{Cs}$ activities for core $C$ were also first found at $26 \mathrm{~cm}$, corresponding to the worldwide atomic bomb testing in approximately 1975 . The good match of the ${ }^{210} \mathrm{~Pb}$ and ${ }^{137} \mathrm{Cs}$ profiles indicated that age measurements are available in this study.

The grain size distribution was analyzed in our study (Figs. 2-4) because of its close relationship with organic matter and the sedimentation rate (Keil et al., 1994). The mean grain size profiles indicated that silt dominated in the studied area. Core A displayed the finest sediment quality, with the median grain size (d50) ranging from 10 to $30 \mu \mathrm{m}$, and the median grain size (d50) displayed slight variability from 0 to $60 \mathrm{~cm}$ except the increased values found from 35 to $50 \mathrm{~cm}$. Core D is coarser than core A, with a range of 20$40 \mu \mathrm{m}$. Similar to core A, the median grain sizes (d50) of core D also showed slight variability, indicating a relatively stable sedimentary environment and good conditions for organic matter preservation in both cores $\mathrm{A}$ and $\mathrm{D}$. In comparison, core $\mathrm{C}$ was characterized by the coarsest sediment quality in the upper section $(0-20 \mathrm{~cm})$, with a range of $40-60 \mu \mathrm{m}$, but with fine sediment in the lower section, indicating a potential increased impact since the 1980s. 


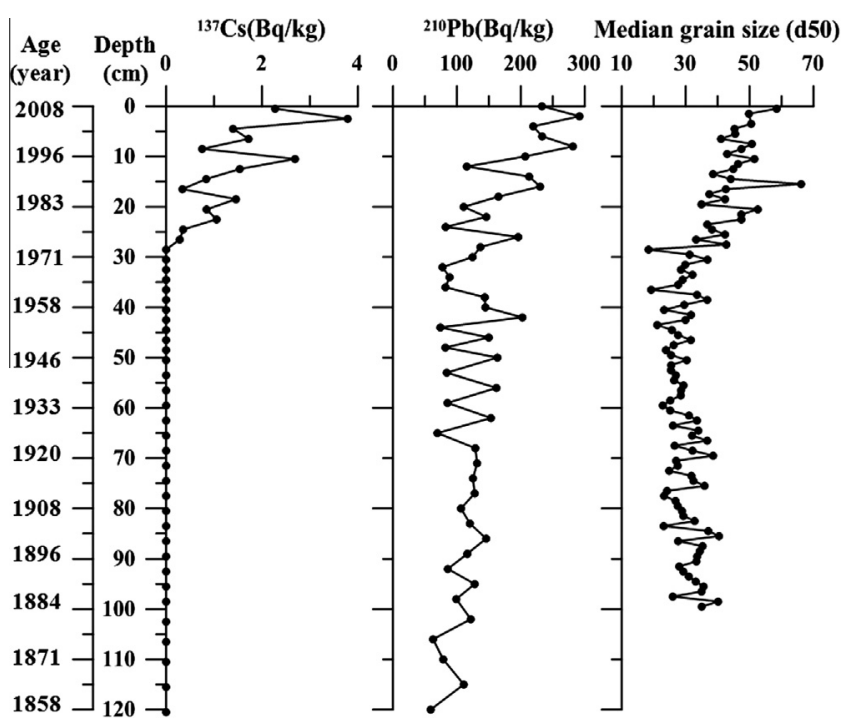

Fig. 4. ${ }^{137} \mathrm{Cs}$ and ${ }^{210} \mathrm{~Pb}$ activities and median grain size (d50) versus depth of core $\mathrm{C}$.

\subsection{The profile of geochemical parameters in core $A$}

The variations of geochemical parameters (TOC, TN, TOC:TN, $\delta^{13} \mathrm{C}$ and $\delta^{15} \mathrm{~N}$ ) in sediment core $\mathrm{A}$ are shown in Fig. 5. The ranges of TOC and TN were $0.36-0.76 \%$ and $0.04-0.09 \%$, respectively (Fig. 5a and b). The pattern of TOC and TN trends in core A displayed a gradual increase in the $0-25 \mathrm{~cm}$ section (=ca. 19752008) and a sudden increase in the $35-50 \mathrm{~cm}$ section, with TOC $>0.6 \%$ and TN $>0.06 \%$ (Fig. $5 a$ and $b$ ). The gradual increase at $0-25 \mathrm{~cm}$ indicated possible nutrient enrichment in the water column that occurred since 1975.

The calculated TOC:TN ratios in the core were narrow, with a range of 8.7-9.9 (Fig. 5c). The $\delta^{13} \mathrm{C}$ values ranged from $-23.0 \%$ to $-21.1 \%$ and the $\delta^{15} \mathrm{~N}$ values ranged from $3.9 \%$ to $8.0 \%$ (Figs. $5 \mathrm{~d}$ and e). A few high and variable values of $\delta^{13} \mathrm{C}$ and $\delta^{15} \mathrm{~N}$ occurred in the upper section of the core (at a depth of $0-40 \mathrm{~cm}$ ), which indicated the increased terrestrial impact, and it matched the rising trend of TOC and TN in the upper section of the core. The values and ranges of the TOC:TN ratios and $\delta^{13} \mathrm{C}$ all tend to indicate that phytoplankton biomass dominated in the organic matter of the sediment.

\subsection{The profile of geochemical parameters in core $D$}

The ranges of TOC and TN in core D were $0.31-0.68 \%$ and $0.04-$ $0.07 \%$, respectively (Fig. $6 a$ and b). Compared with the results in core A, most of the TOC and TN values in core D were much lower. For example, TOC values of $>0.6 \%$ only occurred at the $0-5 \mathrm{~cm}$ depth, and TN values $>0.06 \%$ were only found at the $0-15 \mathrm{~cm}$ depth (Fig. 6a and b). The trends of the TOC and TN values in core D displayed a similarity to those observed in core A with gradually increasing TOC and TN values occurred in the upper section of the core $(0-20 \mathrm{~cm}=\mathrm{ca} .1983-2008)$, however no high values were found from 35 to $50 \mathrm{~cm}$ as in core A (Fig. 6a and b). Compared with core $\mathrm{A}$, core $\mathrm{D}$ showed a more stable sedimentary environment and a slower process of nutrient enrichment.

In a general, the TOC:TN ratios and $\delta^{13} \mathrm{C}$ and $\delta^{15} \mathrm{~N}$ displayed lower values than those in core A (Figs. $6 \mathrm{c}-\mathrm{e}$ ). The TOC:TN ratios ranged from 7.9 to 10.8 , with higher values at a depth of $60-120 \mathrm{~cm}$ and lower values at a depth $15-50 \mathrm{~cm}$. A brief period of decline in TOC:TN ratios occurred at a depth of $0-15 \mathrm{~cm}$ (Fig. 6c). The opposite trend of TOC:TN indicated that the TOC might not increase as fast as the TN in core A. Compared with the results in core $\mathrm{A}$, the $\delta^{13} \mathrm{C}$ values were narrower, with a range of $-23.1 \%$ to $-22.0 \%$, particularly in the upper section of the core, indicating that the source of organic matter is relatively simple (Fig. 6d). The $\delta^{15} \mathrm{~N}$ values ranged from $5.0 \%$ to $6.0 \%$, with a slight increase at a depth of $0-65 \mathrm{~cm}$, indicating a less terrestrial impact than in core A (Fig. 6e). Similar to core A, the values and ranges of TOC:TN and $\delta^{13} \mathrm{C}$ suggested that phytoplankton biomass dominated in the organic matter of the sediment in core D.

\subsection{The profile of geochemical parameters in core $C$}

In comparison, lower and less variable TOC and TN values occurred in core C, with the TOC ranging from $0.38 \%$ to $0.58 \%$ and TN from $0.04 \%$ to $0.06 \%$, respectively, although a very slight increase occurred in the upper section of the core (Fig. 7a and b). The variations of TOC and TN values in core $C$ suggested a lowimpact from eutrophication. However, the TOC:TN ratios in core $\mathrm{C}$ were close to those in core $\mathrm{A}$ and higher than those in core $\mathrm{D}$,

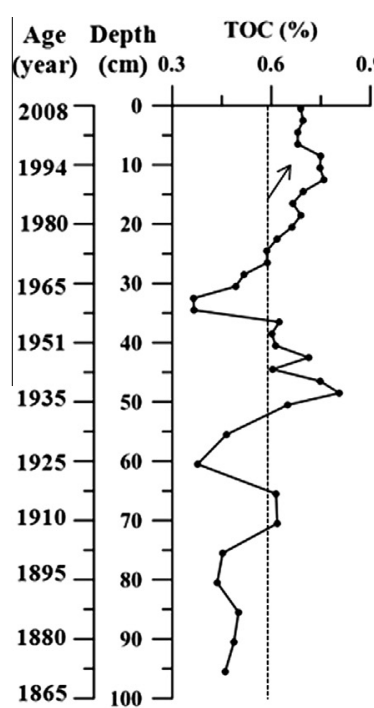

(a)

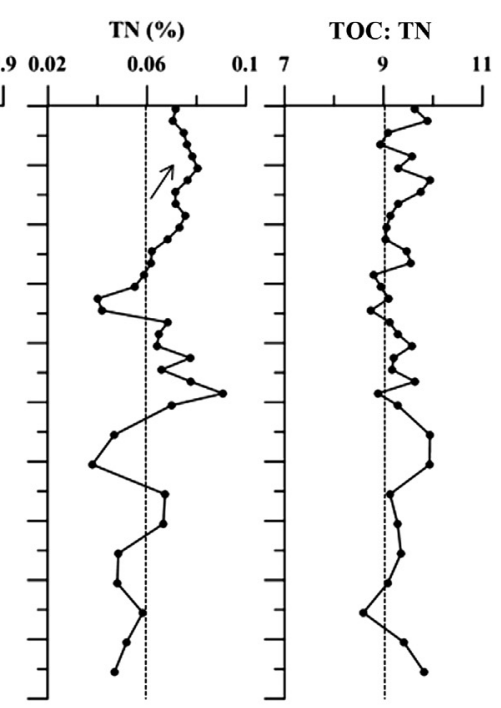

(b)

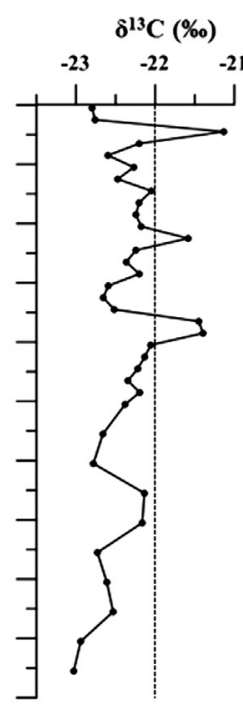

(d)

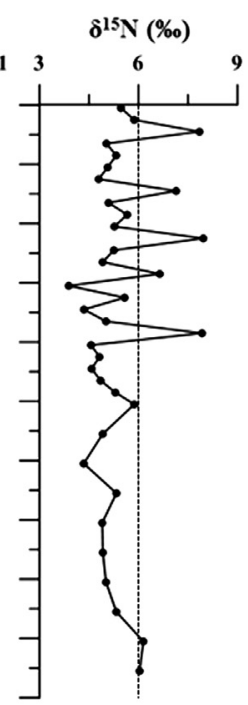

(e)

Fig. 5. The variations of TOC, TN, TOC:TN, $\delta^{13} \mathrm{C}$ and $\delta^{15} \mathrm{~N}$ in core $A$. 


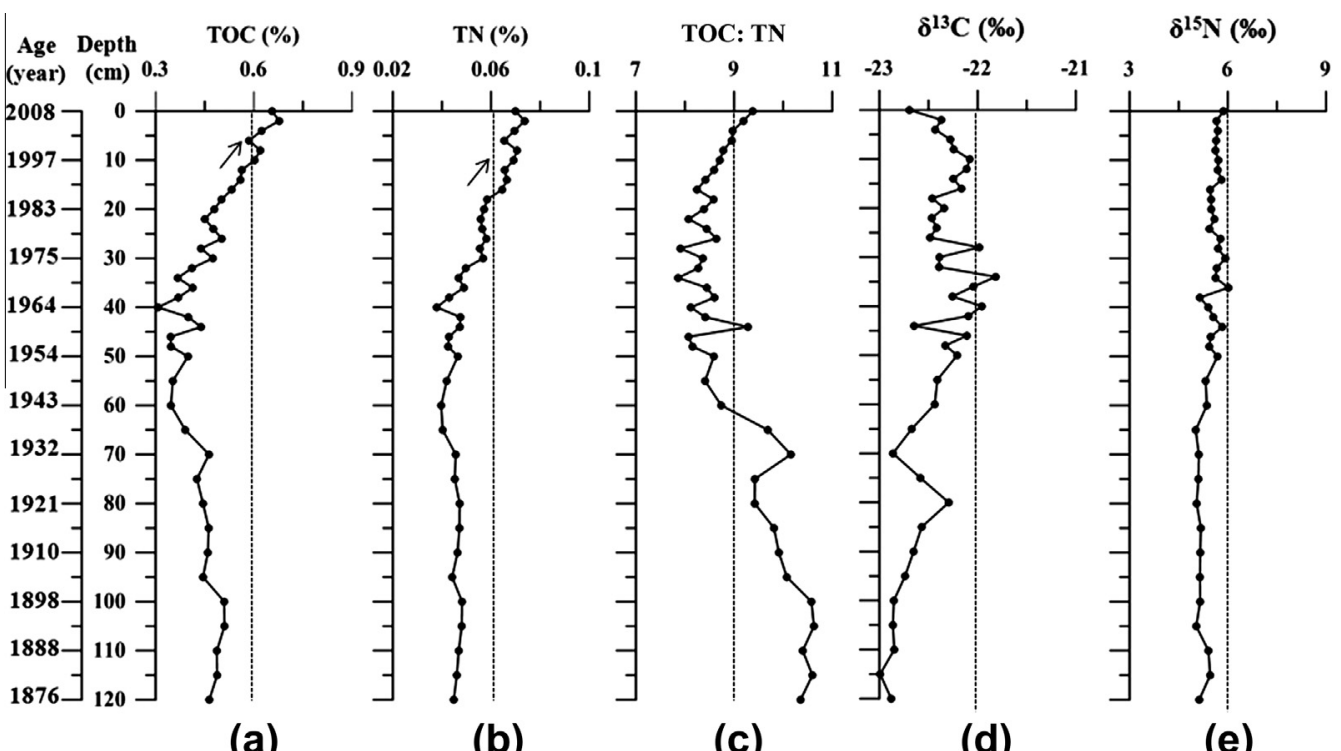

(a)

(b)

(c)

(d)

(e)

Fig. 6. The variations of TOC, TN, TOC:TN, $\delta^{13} \mathrm{C}$ and $\delta^{15} \mathrm{~N}$ in core $\mathrm{D}$.

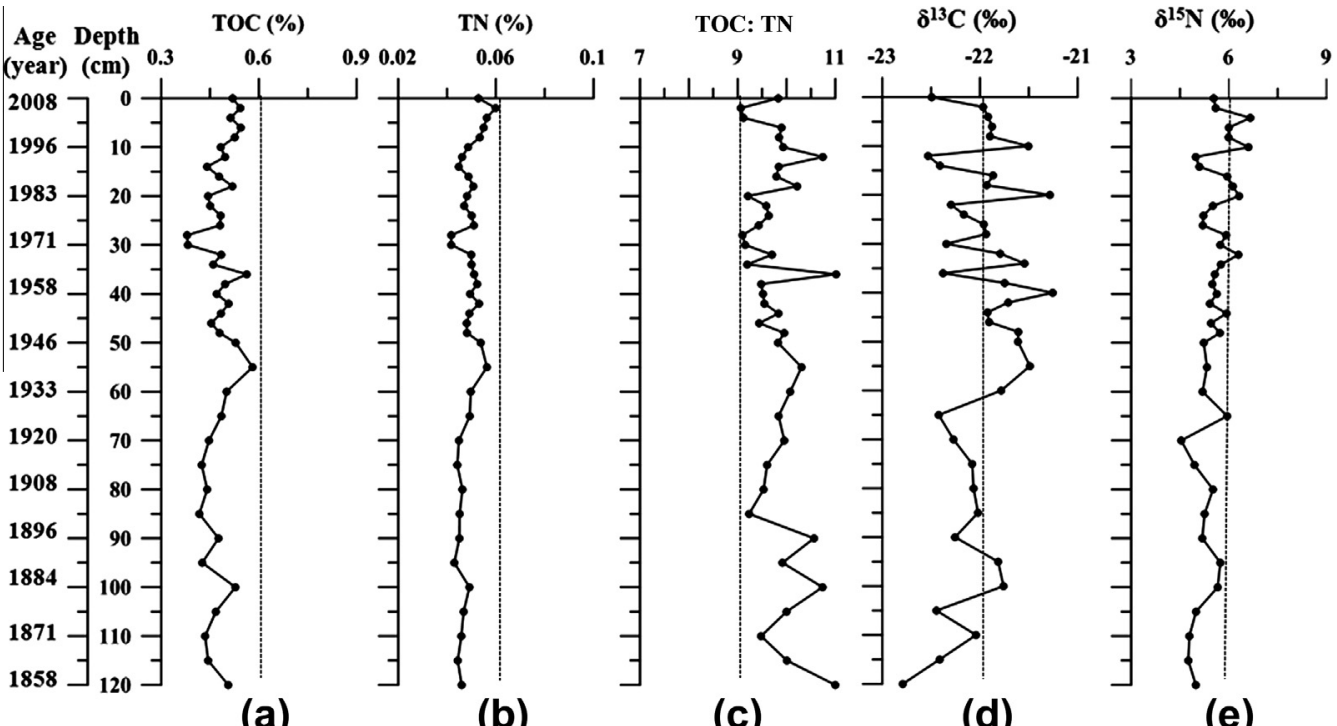

(a)

(b)

(d)

(e)

Fig. 7. The variations of TOC, TN, TOC:TN, $\delta^{13} \mathrm{C}$ and $\delta^{15} \mathrm{~N}$ in core $\mathrm{C}$.

with a range of 9.1-11.0 (Fig. 7c). Moreover, compared with cores $\mathrm{A}$ and $\mathrm{D}, \delta^{13} \mathrm{C}$ displayed the highest and most variable values, with a range of $-22.8 \%$ to $-21.3 \%$, particularly in the upper section of the core (Fig. $7 \mathrm{~d}$ ). The $\delta^{15} \mathrm{~N}$ values ranged from $4.5 \%$ to $6.7 \%$, lower than in core A but slightly higher than in core D, and most of the high $\delta^{15} \mathrm{~N}$ values $(>6.0 \%$ ) in core $\mathrm{C}$ occurred at a depth of 0 $20 \mathrm{~cm}$ (=ca. 1983-2008) (Fig. 7e). The results of TOC:TN, $\delta^{13} \mathrm{C}$ and $\delta{ }^{15} \mathrm{~N}$ indicated that core $\mathrm{C}$ was impacted by terrestrial inputs, although no significant evidence was found for the variation of TOC and TN.

\subsection{Geochemical parameters of SPOM from the water column}

The TOC, TN, TOC:TN ratios, $\delta^{13} \mathrm{C}$ and $\delta^{15} \mathrm{~N}$ of SPOM from the water column at the three sites at the three water depths were measured to verify the results from the surface sediment (Table 1). The highest values of TOC and TN in SPOM occurred at site C, showing a result opposite that observed in the surface sediment. The variations of TOC:TN in SPOM were narrow, with a trend of site D (7.44-7.63) > site A (6.13-7.33) > site C (5.89-7.14), indicating that the organic carbon source composition at site $C$ was more complex, although it did not occur in the surface sediment (Table 1). The $\delta^{13} \mathrm{C}$ values in SPOM were higher at site $\mathrm{C}$ $(-23.8 \%$ to $-22.8 \%)$ compared with sites A $(-23.4 \%$ o to $-23.0 \%$ ) and $\mathrm{D}(-23.1 \%$ to $-23.5 \%$ ) (Table 1$)$. These results were consistent with the results for the surface sediment, and both indicated that the terrestrial impact at site $\mathrm{C}$ was more significant. The $\delta^{15} \mathrm{~N}$ values in SPOM displayed significant differences among the three sites, with a trend of site A $(3.0-4.0 \%)>$ site D $(2.9-4.2 \%$ ) $>$ site C $(1.7-3.2 \%$ ) (Table 1$)$.

Upon combining these parameters in SPOM and sediment, two significant points are observed: (1) at sites A and D, the organic matter source composition was simple, with phytoplankton dominant and (2) at site C, terrestrial organic matter displayed a more obvious signal than at sites A and D, and the high TOC and TN signal in SPOM did not reflect the results for the surface sediment. 
Table 1

Comparison of TOC, TN, TOC:TN, $\delta^{13} \mathrm{C}$ and $\delta^{15} \mathrm{~N}$ between surface sediments and the SPOM at the three sites.

\begin{tabular}{|c|c|c|c|c|c|c|c|}
\hline Material & Site & Depth (m) & TOC (\%) & TN (\%) & TOC:TN & $\delta^{13} \mathrm{C}(\%)$ & $\delta^{15} \mathrm{~N}(\% o)$ \\
\hline \multirow[t]{9}{*}{ SPOM } & A & 1 & 49.15 & 6.71 & 7.3 & -23.3 & 4.0 \\
\hline & & 12 & 43.39 & 6.66 & 6.5 & -23.0 & 3.5 \\
\hline & & 25 & 55.03 & 8.98 & 6.1 & -23.4 & 3.0 \\
\hline & $\mathrm{D}$ & 1 & 47.13 & 6.18 & 7.6 & -23.4 & 2.9 \\
\hline & & 11 & 49.93 & 6.71 & 7.4 & -23.1 & 3.3 \\
\hline & & 22 & 52.70 & 6.92 & 7.6 & -23.5 & 4.2 \\
\hline & $\mathrm{C}$ & 1 & 63.88 & 10.85 & 5.9 & -22.8 & 1.7 \\
\hline & & 5 & 90.31 & 12.65 & 7.1 & -23.8 & 3.2 \\
\hline & & 10 & 67.10 & 10.43 & 6.4 & -23.1 & 2.8 \\
\hline \multirow[t]{3}{*}{ Surface sediment } & A & - & 0.69 & 0.07 & 9.6 & -22.8 & 5.5 \\
\hline & $\mathrm{D}$ & - & 0.66 & 0.07 & 9.4 & -22.7 & 5.9 \\
\hline & C & - & 0.52 & 0.05 & 9.8 & -22.5 & 5.5 \\
\hline
\end{tabular}

\section{Discussion}

In this study, significant rising trends of TOC and TN were found in the upper sections of cores A and D (Figs. 5 and 6), which covered a time span of approximately 1975-2008 and, supported our hypothesis that eutrophication could have occurred in Sishili Bay since the Chinese economic reform in 1978. The result of diatom frustules and dinoflagellate cysts at site A also increased at 1975 and dominant species shifted abruptly. However, this signal was not significant in core $\mathrm{C}$, although TOC and TN displayed a very slight increase in the upper section of the core (Fig. 7). The results from the TOC:TN ratios and $\delta^{13} \mathrm{C}$ and $\delta^{15} \mathrm{~N}$ in the three cores were characterized by the dominance of marine organic matter, with a less or more increased terrestrial signal displayed in the upper section of the cores. Based on these results, human activities related to eutrophication, the differences among the three sites and the variations of the organic matter sources in the sediment are discussed below.

\subsection{Indication of eutrophication from the cores in Sishili Bay}

Since China's economic development in 1978, various human activities have developed quickly around Sishili Bay, including a rapid increase in population, fertilizer use, sewage discharge, shipment, and marine aquaculture, etc. (Fig. 8a-e). Sun et al. (2012) found that metals (e.g., $\mathrm{Cr}, \mathrm{Zn}, \mathrm{As}, \mathrm{Pb}, \mathrm{Cu}$ ) in sediment cores also showed an obvious increase since the 1980s, indicating the impact from the increased human activities. Eutrophic signal was also observed in previous studies. For example, recent survey data from the water column showed that the delivery of nitrate and phosphate derived from these activities has increased nutrient levels and caused substantial eutrophication in Sishili Bay (Zhou et al., 2006; Yu et al., 2009; Wang et al., 2012). Meanwhile, increased harmful algal blooms and phytoplankton biomass in Sishili Bay since the 1990s further demonstrated the impact of increased nutrients (Yu et al., 2009; Hao et al., 2011; Jiang et al., 2011). This increase was recorded in cores $\mathrm{A}$ and $\mathrm{D}$ and was reflected in the upper sections of the cores by the increased TOC and TN.

Core A was collected at a site near the shore and the outlet of the Taozi sewage treatment plant (Fig. 1). Based on historical statistical data, the population increased since 1950 (Fig. 8a), resulted in the increasing organic matters and nitrogen loadings from terrestrial. The high values of TOC, TN in $0-25 \mathrm{~cm}(1975-2008)$ and the high variations of $\delta^{13} \mathrm{C}$ and $\delta^{15} \mathrm{~N}$ between 0 and $40 \mathrm{~cm}$ both showed this. Since the 1970s, the rapid increase in population has led to an increase of economic development in Yantai. Effects from human activities mainly included two periods:one was the effects from the increase of fertilizer use as results of agriculture reform in the early stages of the national economic reform.
Fertilizer use showed a significant increase of in 1975 and quickly reached a peak of $10.5 \times 10^{5}$ tons in 1980 (Fig. 8e). The other was effects from the increase of marine dumping and sewage discharge during 1990s and 2000s (Liu et al., 2013). The increase of growth domestic production mainly happened after 1990s (Fig. 8b), of sewage discharge mainly happened after 1995 (Fig. 8f), and the increase of cargo throughput even happened since 2000 (Fig. 8c and d). Moreover, a significant correlation between TOC and TN $(P<0.01)$ (Table 2), high and variable $\delta^{15} \mathrm{~N}$ values in the upper section of core A (Fig. 5e) and SPOM (Table 1 ) indicated the impact of nitrogen pollution at site A on TOC. This impact was also found in the nutrient analysis of water in Yantai coast, which showed much higher nitrogen concentrations at site A (Wang et al., 2012). Combine the variations of TOC, TN and effects from human activities, increase of fertilizer use matched the increase of TOC and TN since 1970s, and other factors such as the sewage discharge speed up the increase after 1990s. The sudden increase in the $35-50 \mathrm{~cm}$ section corresponded to the increase of grain size related to a sudden increase in coarse silt (Fig. 2), and might being caused by a disturbance from a flood or other land source (Liu et al., 2013).

Core D was collected at a relatively offshore area (Fig. 1) with less human activity. However, increased TOC and TN, indicating eutrophication, was observed in the upper section of core D $(=0-$ $20 \mathrm{~cm}$ ), although the values of TOC and TN were obviously lower than those in core A (Fig. 6). Two factors may help explain these results. First, coastal currents can bring pollution from site A to site D over time. Second is the impact from marine dumping since 1988 near site D. Ji et al. (2003) found environmental deterioration around this region since marine dumping began, and high diatom frustules and cysts were observed in the surface sediment of site D (Liu et al., 2012; Di et al., 2013). This information matched the variations of TOC and TN in core D. Meanwhile, the slight variations of $\delta^{15} \mathrm{~N}$ values in core D (Fig. 6e) and the lower values in SPOM at site $\mathrm{D}$ (Table 1) also suggested a lower eutrophication rate compared with site $A$.

In comparison, no distinct increase in $\mathrm{TOC}$ and $\mathrm{TN}$ was found in core C (Fig. 7), although high TOC and TN occurred in the SPOM measurements at site $C$ (Table 1 ). Core $C$ was collected from a site near scallop aquaculture (Fig. 1). Previous studies have shown that filter-feeding bivalves have a potential use in mitigating the eutrophication pressures in coastal waters (Rice, 2000; Nelson et al., 2004). For example, oyster farming was used to improve the environmental quality of the Chesapeake Bay (Ulanowicz and Tuttle, 1992; Gottlieb and Schweighofer, 1996); mussel farming was used to improve the marine water quality in Sweden (Lindahl et al., 2005); additionally, in Sanggou Bay, a change from a kelp culture to a mixed culture of kelp and bivalves reduced TOC in the sediment from $1.88 \%$ to $0.48 \%$ (Song et al., 2012). These examples may explain why no obvious eutrophic signal occurred at site $C$. Marine aquaculture began in Sishili Bay in the 1960s, but 

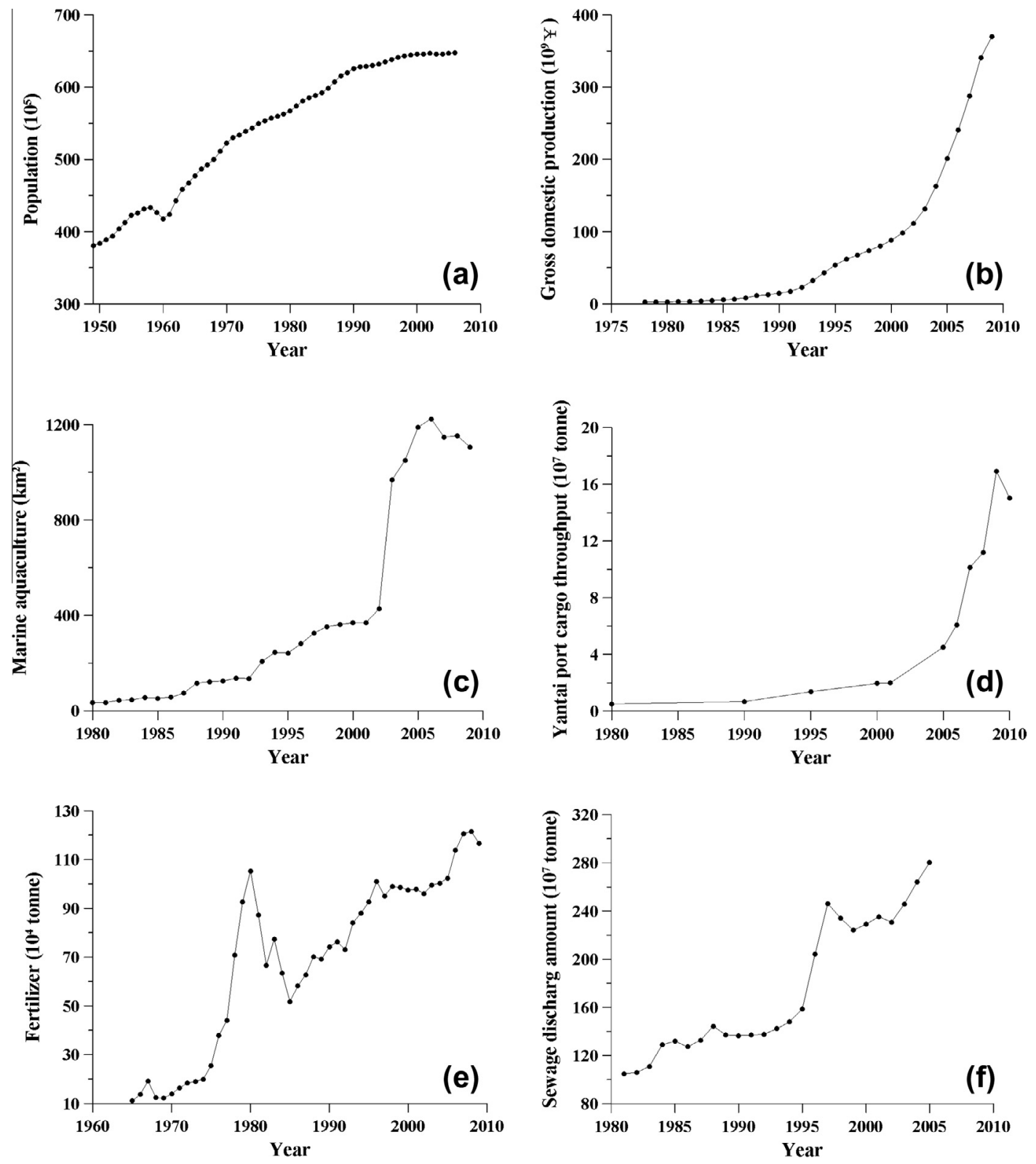

Fig. 8. Variations of human activity factors in Yantai, China (Shandong statistical yearbooks, 2011; Yantai statistical year books, 2011).

Table 2

Pearson correlations between TOC, TN, TOC:TN, $\delta^{13} \mathrm{C}, \delta^{15} \mathrm{~N}$ and BSi of samples in the three sediment cores.

\begin{tabular}{llllll}
\hline Factors & Cores & TOC & TN & TOC:TN & $\delta^{15} \mathrm{~N}$ \\
\hline TOC & A & - & $0.959^{* * *}$ & - & - \\
& D & - & $0.870^{* * *}$ & - & - \\
& C & - & $0.708^{* * *}$ & - & - \\
$\delta^{13} \mathrm{C}$ & $\mathrm{A}$ & - & - & $-0.340^{*}$ & $0.507^{* *}$ \\
& $\mathrm{D}$ & - & - & $-0.866^{* *}$ & $0.477^{* * *}$ \\
& $\mathrm{C}$ & - & - & $-0.364^{*}$ & $0.479^{* * *}$ \\
$\mathrm{BSi}$ & $\mathrm{A}$ & $0.475^{* *}$ & $0.475^{* *}$ & - & - \\
& $\mathrm{D}$ & $0.819^{* *}$ & $0.802^{* *}$ & - & - \\
& $\mathrm{C}$ & $0.359^{*}$ & $0.352^{*}$ & - & - \\
\hline
\end{tabular}

(The BSi data was provided by Li Xin).

** Correlation is significant at the 0.01 level (2-tailed).

* Correlation is significant at the 0.05 level (2-tailed).

large-scale scallop aquaculture was developed in the 1990s, accounting for ca. 70\% of the bay area (Zhao and Wang, 2004). In Sishili Bay, the mitigation of eutrophication by the collection of cultured scallops also reported by Zhou et al. (2006). The high grazing pressure of scallops on phytoplankton and the harvest of scallops significantly reduced the levels of TOC and TON in the seawater. As a result, the TOC and TN contents in the sediment can decline, although the variable TOC:TN ratios and $\delta^{13} \mathrm{C}$ and $\delta^{15} \mathrm{~N}$ indicated the impact on the composition of organic matter. In addition, the scallop aquaculture in Sishili Bay usually operates between May and October. Our SPOM samples in this study were collected in March 2010 before scallop aquaculture started, which may explain the inconsistent results between SPOM and the surface sediment samples at site $C$.

A comparison of the TOC and TN of the three sediment cores in Sishili Bay with results from other coastal and estuarine areas showed that although the three sites were characterized by impacts from different anthropogenic activities, the organic matter contents were all relatively close to the offshore areas of the Pearl River (Zhang, 2006) and the Yangtze River (Feng et al., 2008), but much lower than other bays with distinct human activity effects, such as Daya Bay (Du et al., 2008) and the estuary areas of the Yangtze (Gao et al., 2007) and Pearl (Zhang, 2006) rivers. The 
comparison indicated that the sedimentary environment of Sishili Bay showed less eutrophication pressure and is close to the environment of the offshore areas.

\subsection{Discrimination of organic matter sources from the cores in Sishili Bay}

In this study, combined information from TOC:TN ratios and $\delta^{13} \mathrm{C}$ and $\delta^{15} \mathrm{~N}$ in the cores and SPOM was used to elucidate the origin of organic matter in Sishili Bay. First, the TOC:TN ratios of cores $\mathrm{A}, \mathrm{D}$ and $\mathrm{C}$ were narrow, with ranges of 8.7-9.9, 7.9-10.8, and 9.111.0 (Figs. 5-7), respectively, and significant correlations between TOC and TN were found in the three cores $(P<0.01)$ (Table 2). Based on previous studies (Meyers, 1994; Cifuentes et al., 1996), the organic matter sources of the three sites in our study seemed to be a mixture of marine and terrestrial sources with phytoplankton as the dominant component. However, considering the effects of oxidation and denitrification during sedimentation (Andrews et al., 1998; Waterson, 2005; Kuwae et al., 2006), the organic sources based on the TOC:TN values must be considered with caution, and there is a need to refer the ranges of $\delta^{13} \mathrm{C}$.

If the TOC:TN ratios clearly indicated the organic matter source, a good relationship between the TOC:TN ratio and $\delta^{13} \mathrm{C}$ should exist (Owens, 1985). In this study, significant correlations between the TOC:TN ratio and $\delta^{13} \mathrm{C}$ were found in the three sediment cores $(P<0.05$ for core A and core $C ; P<0.01$ for core $D)$ (Table 2$)$, indicating that the TOC:TN ratios and $\delta^{13} \mathrm{C}$ both could be used to assess the organic matter sources.

The $\delta^{13} \mathrm{C}$ values in the three sediment cores all displayed narrow ranges of $-21.1 \%$ o to $-23.0 \%$ (core $A$ ), $-22.0 \%$ o to $-23.1 \%$ (core D) and $-22.8 \%$ to $-21.3 \%$ (core C), respectively. The corresponding $\delta^{13} \mathrm{C}$ values of the SPOM water column at the three sites were $-23.4 \%$ to $-23.0 \%$ (core A), $-23.5 \%$ to $-23.1 \%$ (core D) and $-22.8 \%$ to $-21.3 \%$ (core C), respectively. According to Chen et al. (2012), the $C_{3}$ plants around our study area had $\delta^{13} \mathrm{C}$ values of $-26 \%$ to $-27 \%$. The $\delta^{13} \mathrm{C}$ values for the three cores in our study were slightly lower than those of phytoplankton and higher than those of the $C_{3}$ plants. Because the $\delta^{13} \mathrm{C}$ values of the $C_{4}$ plants range from $-9 \%$ to $-16 \%$, with a mean value of $-13 \%$ (Pancost and Boot, 2004), a mixture of $C_{3}$ and $C_{4}$ plants could also result in a $\delta^{13} \mathrm{C}$ value of $-23 \%$. Corn is the dominant $\mathrm{C}_{4}$ plant in our study area. The TOC:TN ratios of corn are 60-200, much higher than those of our sediment samples, indicating that the terrestrial input of $\mathrm{C}_{4}$ plants could most likely be neglected and that the high $\delta^{13} \mathrm{C}$ value is most likely related to aquatic biomass. Because phytoplankton are dominant in Sishili Bay and are the most important source of BSi in the sediment (Hao et al., 2011; Jiang et al., 2011), positive correlation between BSi and TOC should be found in our study if the estimation of organic matter sources in Sishili Bay is valid. Correlations between TOC and BSi were thus analyzed in our study. Significant positive correlations between TOC and BSi for the three sediment cores $(P<0.01$ for core A and $D ; P<0.05$ for core $C$ ) were found (Table 2 ), indicating the major contribution of diatoms on TOC. All the above information enhanced the discrimination of organic matter sources in the cores from Sishili Bay, which appeared to be dominated by marine sources related to phytoplankton.

Although the proportion of terrestrial inputs was low in the sediment of Sishili Bay, the rising trend in recent decades and the significant difference between the three sites caused by different human activities and river input were still evident. Site $A$ is close to the sewage discharge outlet, with higher nutrient loadings compared with the other two sites, especially for nitrogen loadings (Wang et al., 2012). The correlations between TOC and TN and between $\delta^{13} \mathrm{C}$ and $\delta^{15} \mathrm{~N}$ in core A were more significant than in the other two cores (Table 2 ). The relatively higher and more variable $\delta^{15} \mathrm{~N}$ values occurred in the section of $0-40 \mathrm{~cm}$ in core A also indicated the high terrestrial nitrogen loadings. The results showed the significant linear impact of increased TN on the content of TOC. However, the correlations between TOC:TN ratios and $\delta^{13} \mathrm{C}$ and between TOC and BSi in core A were weaker than in core D (Table 2), and the TOC:TN ratios were higher (Fig. 5), indicating that the terrestrial organic matter loadings contributed to the TOC contents in core A more than in core D.

Site $C$ is located in the bay with a few nearby small rivers (Fig. 1). Compared with the other two cores, the TOC:TN ratio ranges were wider and the $\delta^{13} \mathrm{C}$ values were more variable in core $\mathrm{C}$, indicating diverse organic matter sources and the likely impact from rivers (Fig. 7). However, the feeding behavior of the cultured scallops in this area consumed part of the TOC and TN and weakened the rising trends in core C. Meanwhile, the correlations between BSi and TOC and TN, between $\delta^{13} \mathrm{C}$ and $\delta^{15} \mathrm{~N}$, and between TOC and TN were weaker than the other two cores, further indicating the more impact from terrestrial organic matter sources and aquaculture.

In comparison, site $\mathrm{D}$ is located in a relatively offshore area with less terrestrial loadings (Fig. 1). The values and ranges of TOC:TN ratios, $\delta^{13} \mathrm{C}$ and $\delta^{15} \mathrm{~N}$ and the significant correlation between TOC:TN ratios and $\delta^{13} \mathrm{C}$ indicated a simpler organic matter source composition, and the effects from terrestrial loadings are lighter. Moreover, the highest correlation coefficient of TOC and BSi indicated the significant contribution of phytoplankton to the total TOC in core D (Table 2).

The ranges of TOC:TN ratios in Sishili Bay were close to the samples from relatively offshore areas, such as the adjacent Pearl River shelf (Zhang, 2006), but narrower than the sediments from estuary areas, including Jiaozhou Bay (Dai et al., 2007; Li et al., 2008) and the Pearl River estuary (Zhang, 2006). The $\delta^{13} \mathrm{C}$ values were also close to the adjacent Pearl River shelf (Zhang, 2006) and the offshore area of the Yangtze River (Feng et al., 2008). These values were lower than those of areas with obvious anthropogenic loadings, such as Gokasho Bay (Yokoyama et al., 2006) and the Gulf of Mexico (GoñI et al., 1998). The ranges of $\delta^{13} \mathrm{C}$ values were wider than those of offshore areas such as the adjacent Pearl River shelf (Zhang, 2006) and the offshore area of the Yangtze River (Feng et al., 2008) and were much narrower than those of the estuary areas, such as the Yangtze River estuary (Gao et al., 2007) and the Pearl River estuary (Zhang, 2006). Based on all the comparisons, the organic matter sources in Sishili Bay were relatively simple, with less terrestrial loadings compared with other estuaries, and they showed the characteristics of offshore marine carbon biomass as the dominant source.

\section{Conclusions}

Three sediment cores covering a 100-year span in Sishili Bay displayed variations in total carbon and nitrogen and their isotope composition. There were indications of a eutrophic trend starting in the 1975 in Sishili Bay. The organic matter composition indicated an increased terrestrial loading related to human activity (e.g., fertilizer use, sewage discharge, marine dumping) and river input, although marine organic matter sources still dominated in Sishili Bay. Among the human activities analyzed, fertilizer use matched the increase of TOC and TN from 1975, and sewage discharge, marine dumping and cargo throughput speed up the increase from 1990s to 2000s. In addition, the feeding behavior of cultured scallops contributed to a significant mitigation of eutrophication pressures in Sishili Bay. Compared with other coastal areas, the sedimentary environment of Sishili Bay showed less anthropogenic impacts, with relatively low terrestrial loadings, and it is close to the environment of offshore areas. 


\section{Acknowledgements}

The authors thank Gaël Guillou for helping in the isotope ratio analysis of the samples. We appreciate constructive comments from Prof. John Morrison during the preparation of the manuscript. This study was funded by the National Nature Science Foundation of China (Nos. 40976097 and 41106101), the NSFC-CNRS cooperation project (No. 41111130194) and International (Regional) Cooperation and Exchange Projects (No. 41250110529).

\section{References}

Andrews, J.E., Greenaway, A.M., Dennis, P.F., 1998. Combined carbon isotope and $C / N$ ratios as indicators of source and fate of organic matter in a poorly flushed, tropical estuary: Hunts Bay, Kingston Harbour, Jamaica. Est. Coast Shelf Sci. 46, 743-756.

Appleby, P.G., Nolan, P.J., Gifford, D.W., Godfrey, M.J., Oldfield, F., Anderson, N.J., Battarbee, $1986 .{ }^{210} \mathrm{~Pb}$ dating by low background gamma counting. Hydrobiologia 143, 21-27.

Bratton, J.F., Colman, S.M., Seal, R.R., 2003. Eutrophication and carbon sources in Chesapeake Bay over the last $2700 \mathrm{yr}$ : human impacts in context. Geochim. Cosmochim. Acta 67, 3385-3402.

Chai, C., Yu, Z., Song, X., Gao, X., 2006. The status and characteristics of eutrophication in the Yangtze River (Changjiang) estuary and the adjacent East China Sea, China. Hydrobiologia 563, 313-328.

Chen, Y., Cai, W., Huang, G., Li, J., Zhang, G., 2012. Stable carbon isotope of black carbon from typical emission sources in China. Environ. Sci. 33, 673-678 (in Chinese, with English abstracts).

Cifuentes, L.A., Coffins, R.B., Solorzano, L., Cardenas, W., Espinoza, J., Twilley, R.R., 1996. Isotopic and elemental variations of carbon and nitrogen in a mangrove estuary. Est. Coast Shelf Sci. 43, 781-800.

Cohen, R.A., Fong, P., 2005. Experimental evidence supports the use of $\delta^{15} \mathrm{~N}$ content of the opportunistic green macroalga Enteromorpha Intestinalis (Clorophyta) to determine nitrogen sources to estuaries. J. Phycol. 41, 287-293.

Cooper, S.R., McGlothlin, S.K., Madritch, M., Jones, D.L., 2004. Paleaecological evidence of human impacts on the Neuse and Pamlico estuaries of North Carolina, USA. Estuaries 27, 617-633.

Dai, J., Song, J., Li, X., Yuan, H., Li, N., Zheng, G., 2007. Environmental changes reflected by sedimentary geochemistry in recent hundred year of Jiaozhou Bay, North China. Environ. Pollut. 145, 656-667.

de Jonge, V.N., Elliott, M., Orive, E., 2002. Causes, historical development, effects and future challenges of a common environmental problem: eutrophication. Hydrobiologia 475-476, 1-19.

Di, B., Liu, D., Wang, Y., Dong, Z., Li, X., Shi, Y., 2013. Diatom and silicoflagellate assemblages in modern surface sediments associated with human activity: a case study in Sishili Bay, China. Ecol. Ind. 24, 23-30.

Dong, Z., Liu, D., Keesing, J.K., 2010. Jellyfish blooms in China: dominant species, causes and consequences. Mar. Pollut. Bull. 60, 954-963.

Du, J., Mu, H., Song, H., Yan, S., Gu, Y., Zhang, J., 2008. 100 years of sediment history of heavy metals in Daya Bay, China. Water Air Soil Pollut. 190, 343-351.

Feng, X., Jing, X., Yu, X., Li, H., Chen, J., Qian, J., 2008. Sedimentary records of eutrophication in the Changjiang Estuary upwelling area over last $100 \mathrm{a}$. Acta Oceanol. Sin. 27, 49-61.

Fry, B., Sherr, E.B., 1984. $\Delta{ }^{13} \mathrm{C}$ measurements as indicators of carbon flow in marine and freshwater ecosystems. Contrib. Mar. Sci. 27, 13-47.

Gao, J., Wang, Y., Pan, S., Zhang, R., Li, J., Bai, F., 2007. Source and distribution of organic matter in seabed sediments of the Changjiang River estuary and its adjacent sea area. Acta Geogr. Sin. 62, 981-991.

Goldberg, E.D., 1963. Geochronology with ${ }^{210} \mathrm{~Pb}$. In: Radioactive Dating. I.A.E.A, Vienna, pp. 121-131.

Goñi, M.A., Ruttenberg, K.C., Eglinton, T.I., 1998. A reassessment of the sources and importance of land-derived organic matter in surface sediments from the Gulf of Mexico. Geochim. Gosmochim. Acta 62, 3055-3075.

Gonneea, M.E., Paytan, A., Herrera-Silveira, J.A., 2004. Tracing organic matter sources and carbon burial in mangrove sediments over the past 160 years. Est. Coast. Shelf Sci. 61, 211-227.

Gottlieb, S.J., Schweighofer, M.E., 1996. Oysters and the Chesapeake Bay ecosystems: a case for exotic species introduction to improve environmental quality? Estuaries 19, 639-650.

Graham, M.G., Eaves, M.A., Farmer, J.G., Dobson, J., Fallick, A.E., 2001. A study of carbon and nitrogen stable isotope and elemental ratios as potential indicators of source and fate of organic matter in sediments of the Forth estuary, Scotland. Est. Coast. Shelf Sci. 52, 375-380.

Hao, Y., Tang, D., Yu, L., Xing, Q., 2011. Nutrients and chlorophyll-a anomalies in redtide periods of 2003-2008 in the Sishili Bay, China. Chin. J. Oceanol. Limnol. 29, 664-673.

Ji, L., Wang, R., Liu, C., Wang, G., Ma, G., Zhang, X., Jiang, J., 2003. Environmental monitoring and contrast evaluation on Yantai marine dumping site. Mar. Sci. Bull. 22, 53-59 (in Chinese, with English abstract).

Jiang, J., Liu, D., Di, B., Dong, Z., Wang, Y., Wang, Y., Shi, Y., 2011. Seasonal changes of phytoplankton community and its indication of environment in Sishili Bay, Yantai. Acta Oceanol. Sin. 33, 151-164 (in Chinese, with English abstracts).
Joshi, S.R., Shukla, B.S., 1991. Ab initio derivation of formulations for ${ }^{210} \mathrm{~Pb}$ dating of sediments. J. Radioanal. Nucl. Chem. 148, 73-79.

Keil, R.G., Montluçon, D.B., Prahl, F.G., Hedges, J.I., 1994. Sorptive preservation of labile organic matter in marine sediments. Nature (London) 370 , 549-552.

Kuwae, M., Yamaguchi, H., Tsugeki, N.T., Miyasaka, H., Fukumori, K., Ikehara, M., Genkai-Kato, M., Omori, K., Sugimoto, T., Ishida, S., Takeoka, H., 2006. Spatial distribution of organic and sulfur geochemical parameters of oxic to anoxic surface sediments in Beppu Bay in southwest Japan. Est. Coast. Shelf Sci. 72, 111.

Li, X., Yuan, H., Li, N., Song, J., 2008. Organic carbon source and burial during the past one hundred years in Jiaozhou Bay, North China. J. Environ. Sci. 20, 551-557.

Lindahl, O., Hart, R., Hernroth, B., Kollberg, S., Loo, L.O., Olrog, L., Rehnstam-Holm, A.S., Svensson, J., Svensson, S., Syversen, U., 2005. Improving marine water quality by mussel farming: a profitable solution for Swedish society. Ambio 34 131-138.

Liu, D., Shi, Y., Di, B., Sun, Q., Wang, Y., Dong, Z., Shao, H., 2012. The impact of different pollution sources on modern dinoflagellate cysts in Sishili Bay, Yellow Sea. China. Mar. Micropaleontol. 84-85, 1-13.

Liu, D., Shen, X., Di, B., Shi, Y., Keesing, J.K., Wang, Y., Wang, Y., 2013. Palaeoecological analysis of phytoplankton regime shifts in response to coastal eutrophication. Mar. Ecol. Prog. Ser. 475, 1-14.

Liu, S., Zhang, J., Chen, H., Zhang, G., 2005. Factors influencing nutrient dynamics in t he eutrophic Jiaozhou Bay, North China. Prog. Oceanogr. 66, 66-85.

Matson, E.A., Brinson, M.M., 1990. Stable carbon isotopes and the C:N ratio in the estuaries of the Pamlico and Neuse Rivers, NC. Limnol. Oceanogr. 35, 12901300.

Meyers, P.A., Lallier-Verges, E., 1999. Lacustrine sedimentary organic matter records of Late Quaternary paleoclimates. J. Paleontol. 21, 345-372.

Meyers, P.A., 1994. Preservation of elemental and isotopic source identification of sedimentary organic matter. Chem. Geol. 114, 289-302.

Mishima, Y., Hoshika, A., Tanimoto, T., 1999. Deposition rates of terrestrial and marine organic carbon in the Osaka Bay, Seto Inland Sea, Japan, determined using carbon and nitrogen stable isotope ratios in the sediment. J. Oceanogr. 55, $1-11$.

Nelson, K.A., Leonard, L.A., Posey, M.H., Alphin, T.D., Mallin, M.A., 2004. Using transplanted oyster (Crassostrea virginica) beds to improve water quality in small tidal creeks: a pilot study. J. Exp. Mar. Biol. Ecol. 298, 347-368.

Ogrinc, N., Fontolan, G., Faganei, J., Covelli, S., 2004. Carbon and nitrogen isotope compositions of organic matter in coastal marine sediments (the Gulf of Trieste, N Adriatic Sea): indicators of sources and preservation. Mar. Chem. 95, 163181.

Oldfield, F., Appleby, P.G., 1984. Empirical testing of ${ }^{210} \mathrm{~Pb}$ dating models. In: Haworth, E.Y., Lund, J.G. (Eds.), Lake Sediments and Environmental History. Leicester Univ Press, pp. 93-124.

Owens, N.J.P. 1985. Variations in the natural abundance of $15 \mathrm{~N}$ in estuarine suspended particulate matter: a specific indicator of biological processing. Est. Coast. Shelf Sci. 20, 820-825.

Pancost, R.D., Boot, C.S., 2004. The palaeoclimatic utility of terrestrial biomarkers in marine sediments. Mar. Chem. 92, 239-261.

Ramaswamy, V., Gaye, B., Shirodkar, P.V., Rao, P.S., Chivas, A.R., Wheeler, D., Thwin, S., 2008. Distribution and sources of organic carbon, nitrogen and their isotopic signatures in sediments from the Ayeyarwady (Irrawaddy) continental shelf, northern Andaman Sea. Mar. Chem. 111, 137-150.

Rice, M.A., 2000. A review of shellfish restoration as a tool for coastal water quality management. Environ. Cape Cod 3, 1-8.

Sampaio, L., Freitas, R., Máguas, C., Rodrigues, A., Quintino, V., 2010. Coastal sediments under the influence of multiple organic enrichment sources: an evaluation using carbon and nitrogen stable isotopes. Mar. Pollut. Bull. 60, 272 282.

Song, X., Yang, Q., Sun, Y., Yin, H., Jiang, S., 2012. Study of sedimentary section records of organic matter in Sanggou Bay over the last 200 years. Acta Oceanol. Sin. 34, 120-126 (in Chinese, with English abstracts)

Sun, Q., Liu, D., Liu, T., Di, B., Wu, F., 2012. Temporal and spatial distribution of trace metals in sediments from the northern Yellow Sea coast, China: implications for regional anthropogenic processes. Environ. Earth Sci. 66, 697-705.

Teranes, J.L., Bernasconi, S.M., 2000. The record of nitrate utilization and productivity limitation provided by $\delta^{15} \mathrm{~N}$ values in lake organic matter-a study of sediment trap and core sediments from Baldeggersee, Switzerland. Limnol. Oceanogr. 45, 801-813.

Thornton, S.F., McManus, J., 1994. Application of organic carbon and nitrogen stable isotope and $C / N$ ratios as source indicators of organic matter provenance in estuarine systems: evidence from the Tay estuary. Est. Coast. Shelf Sci. 38, 219233.

Ulanowicz, R.E., Tuttle, J.H., 1992. The trophic consequences of oyster stock rehabilitation in Chesapeake Bay. Estuaries 15, 298-306.

Waterson, E.J., 2005. Sources of sedimentary organic matter in the Mississippi River and adjacent Gulf of Mexico. Master thesis, The College of William and Mary in Virginia.

Wang, Y., Liu, D., Dong, Z., Di, B., Shen, X., 2012. Temporal and spatial distributions of nutrients under the influence of human activities in Sishili Bay, northern Yellow Sea of China. Mar. Pollut. Bull. 64, 2708-2719.

Wu, Y., Zhang, J., Zhang, Z., Ren, J., Cao, J., 2002. Seasonal variability of stable carbon and nitrogen isotope of suspended particulate matter in the Changjinag River. Oceanol. Liminol. Sin. 33, 546-552 (in Chinese, with English abstracts). 
Wu, Y., Zhou, C., Zhang, Y., Pu, X., Li, W., 2001. Evolution and causes of formation of Gymnodinium Sanguineum bloom in Yantai Sishili Bay. Oceanol. Limnol. Sin. 32, 157-167 (in Chinese, with English abstracts).

Yokoyama, H., Abo, K., Ishihi, Y., 2006. Quantifying aquaculture-derived organic matter in the sediment in and around a coastal fish farm using stable carbon and nitrogen isotope ratios. Aquaculture 254, 411-425.

Yu, L., Hao, Y., Cai, Y., 2009. Annual variation of nutrient and Chla during HABs' periods in Sishili Bay. Mar. Environ. Sci. 28, 558-561 (in Chinese, with English abstracts).

Zhang, L., 2006. A study on the distribution, origin and early diagenesis of organic matter in Pearl River estuary and adjacent shelf. Doctoral thesis, Guangzhou Institute of Geochemistry, Chin. Acad. Sci. (in Chinese, with English abstracts).
Zhang, R., Dong, Y., 1990. Analysis of conditions of natural environment in sea areas for pollutant discharge and the study on pathways of pollutant transport in Yantai. Coast. Engineering 9, 35-44 (in Chinese with English abstracts).

Zhao, W., Wang, J., 2004. Colloidal organic carbon nitrogen and phosphorus in Yantai Sishili Bay aquaculture water. J. Ji'nan Univ. (Sci. Tech.) 18, 132-135 (in Chinese, with English abstracts).

Zhou, Y., Yang, H., Zhang, T., Qin, P., Xu, X., Zhang, F., 2006. Density-dependent effects on seston dynamics and rates of filtering and biodeposition of the suspension-cultured scallop Chlamys farreri in a eutrophic bay (northern China): an experimental study in semi-in situ flow-through systems. J. Mar. Sys. 59, 143-158. 